\title{
Digital Trends in the Financial Environment
}

\author{
Gilian Fedotova ${ }^{1, *}$, and Yuldash Mamengayev ${ }^{2}$ \\ ${ }^{1}$ Volga region research Institute of production and processing of meat and dairy products, 400131 \\ Volgograd, Russia \\ ${ }^{2}$ Moscow State University of Technology and Management named after K.G. Razumovsky, 109004 \\ Moscow, Russia
}

\begin{abstract}
The relevance of the research topic is dictated by the ongoing processes of transition to the digital sphere of all operations, mechanisms of interaction and provision of services under the conditions of the introduced quarantine measures. The second wave of coronavirus infection that swept the world in the fall of 2020 is forcing a significant revision of the technology for providing many services, including financial ones. In this regard, it is necessary to constantly search for and improve digital technologies, to intensify intellectual and innovative activities. The results obtained lay the foundation for building a new image of the financial market based on AI technologies. New financial institutions operating on artificial intelligence technologies allow many operations and business processes to be performed remotely. Intelligent insights are exactly the kind of products that can be digitally acquired and generated remotely. The formed digital financial infrastructure allows you to quickly enough finance intellectual development and attract investments in this industry.
\end{abstract}

\section{Introduction}

The current level of economic development of the country is based on the full-scale implementation of digital technologies in all spheres of public life, providing remote service and data exchange. The situation with the COVID-2019 pandemic has accelerated the processes of informatization of Russian society. The Internet is becoming not just a pleasant resource for communication of the most creative part of the population, but actually an irreplaceable virtual online platform for the formation of network or personal interaction. In addition, many of the usual operations people perform on a daily basis (buying products, paying bills, holding business meetings, etc.) are becoming remote due to the development and launch of the corresponding services by many companies. The increased demand for online services has led to an increase in the popularity of public cloud services and technologies for interactive interaction between remote users, which increases the growth of Internet traffic.

So, the main reasons for the significant growth in Internet traffic are:

- transfer of employees by employers to remote work, involving interaction via the Internet;

*Corresponding author: g_evgeeva@mail.ru 
- transfer of schoolchildren and students to distance learning, also using the Internet;

- $\quad$ increase in demand and supply for delivery services of food and non-food goods, as well as services provided remotely (payment services, educational services, services of state and municipal authorities);

- increase in demand for entertainment video and game content posted on the resources of streaming digital platforms (Netflix, Disney, Amazon, Tvitch, etc.);

- forced expansion of interpersonal interaction in the virtual space of social networks and messengers (Facebook, Instagram, VK, Whatsapp, Viber, etc.).

In this connection, the course of building an information society adopted by the Government of the Russian Federation since 2017 justifies its purpose, since a platform for remote management of accounts, data, reports has actually been formed. In this direction of development, financial technologies (Fintech) are rapidly developing, the core of which is banking, that is, receiving remote banking services $24 / 7$. Today, not only virtual platforms of traditional lending institutions have been formed, but also neobanks have appeared, which initially operate online. It is these banks that determine the main trends in the development of the Russian financial market. According to Bloomchain, at the end of 2019, Russia ranks 3rd in terms of the spread of financial technologies in the business environment. (Fig. 1).

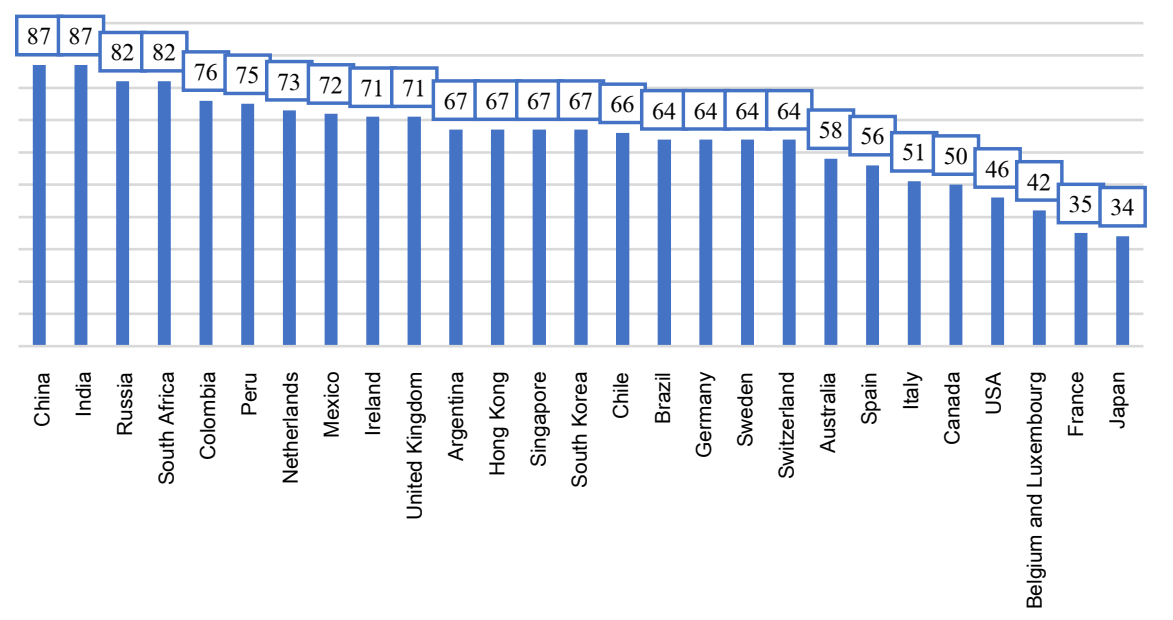

Fig. 1. Russias place in the global FINTECH market among 27 countries, $\%[1,3]$.

In fact, the position of Russia in the financial technology market shown in Figure 1 demonstrates the demand for online financial services, the involvement of financial flows in non-cash circulation and high penetration into the everyday life of the banking population. Today, new opportunities are opening up for the implementation of the most advanced Fintech solutions (AI, BigData, blockchain, open APIs, remote identification, cloud services, etc.).

\section{Main Trends in Digitalization of the Russian Financial Market}

Modern financial technologies become more complex every year and change the very architecture of the financial market. Thanks to the introduction of digital technologies, the infrastructure of the Russian financial market has been transformed and become more competitive, integrated with the international financial market and allows Russian companies to operate in advanced financial markets $[2,4]$. Of all the many innovations that 
are being introduced into the work of segments of the financial market, the main promising trends can be distinguished as follows:

- RPA systems, which are software for automating business processes;

- disappearance of physical money, that is, a full-scale transition to online bill payment and non-cash transfers;

- expanding access to online banking services;

- displacement of the technological center to the Asian region;

- Regtech - Regulatory technologies help companies comply with regulatory requirements through big data, cloud computing, artificial intelligence, blockchain and other innovations.

In fact, today the level of penetration of financial technologies into public life in Russia is quite high, since the average level is $82 \%$. The peculiarity of the Russian financial market is the rapid growth of the sector of virtual financial institutions or neobanks, which initially position themselves as companies without offline offices. Neobanks can be either independent financial institutions with their own license, or operate on the basis of an existing bank. Neobanks are formed according to one of 5 models and offer a wider range of online services. It is very difficult to assess this market due to the lack of complete reporting data on the activities of such companies, but nevertheless it is possible to determine their capitalization cost. The largest neobanks operate in Europe and the USA. There are 15 main neobanks with different capitalization levels in Russia.

Let's consider the main models of organizing neobanks in Russia. (Fig. 2).

In addition to banking, other sectors of the financial market are also developing: investment, insurance, public finance, corporate finance and personal finance. Digital technologies have come to all spheres, which makes it necessary for the financial megaregulator to completely restructure the entire financial infrastructure of the country and create new platforms for interaction in the online environment.

Thus, we see that financial services are becoming more accessible, open and involving an increasing number of participants in ongoing projects. For the innovation sphere, these changes are becoming a favorable factor for finding and expanding the investment market. Financial injections in this area will allow accumulating the processes of generating new ideas and new products in the context of the growing pace of digitalization in all areas. It should be noted that it is in this area that new technological solutions and approaches to traditional operations and processes are being created. 


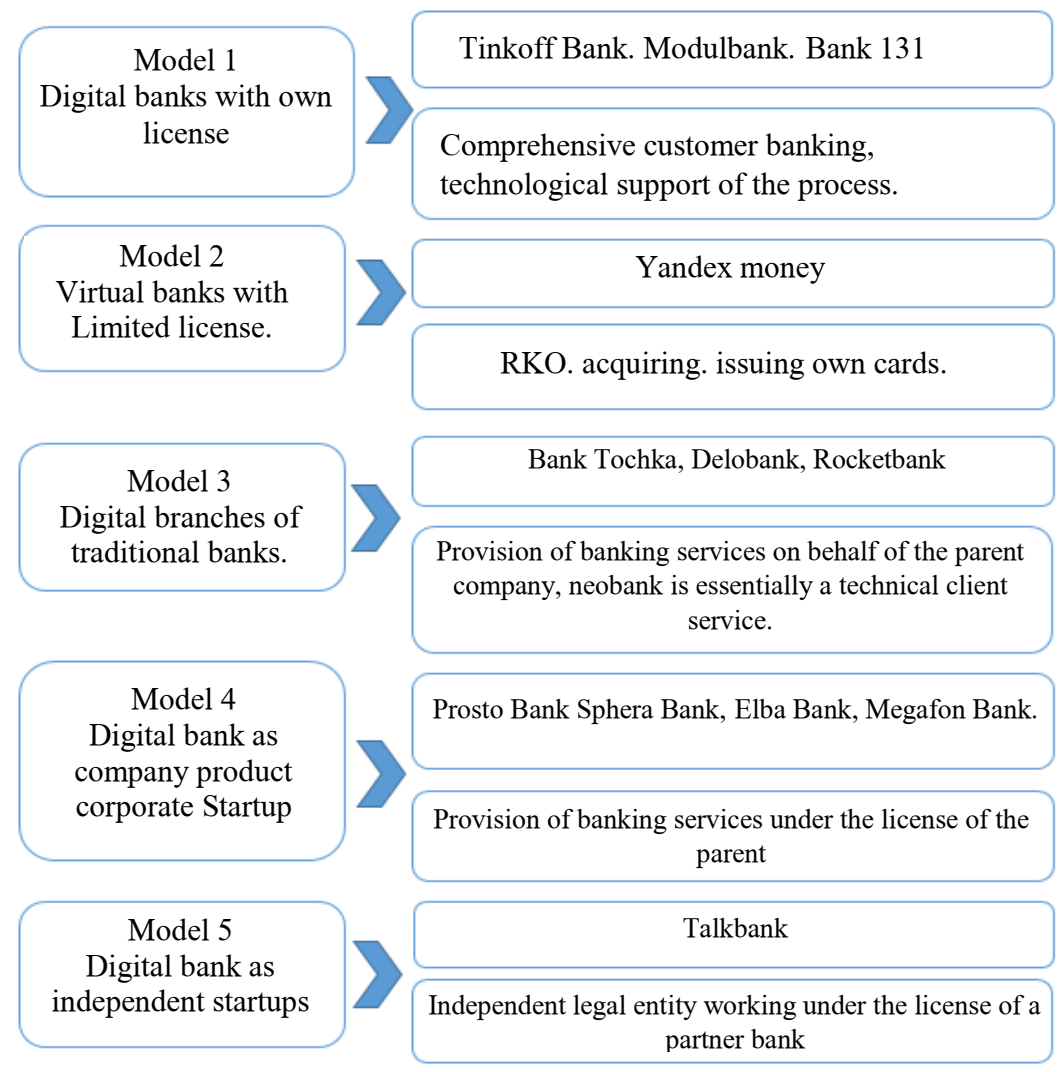

Fig. 2. Work models of neobanks in Russia, [2, 3]

Despite regulatory and other possible barriers to market entry, there is an increase in demand for FinTech services in the areas related to servicing individuals, lending to business start-ups, and managing private capital. Many high-tech innovative companies are emerging, operating in the online environment, offering their services to finance new ideas and projects, with which traditional companies will find it increasingly difficult to compete if they do not use the latest technological advances [5].

An example is a new tool, the DeNovo online platform, to identify more cost-effective ways to comply with regulatory requirements. The product has already been in use in the EU and Asia as a new private wealth management application, with nearly 1,000 products, none of which shall be commissioned. This experience is implemented in all areas of financing and allows you to increase the client base through online service offerings and a personalized approach to servicing clients with lower service offers.

Online project financing allows many startups to start implementation, not only in traditional spheres but also in intelligent industries. In addition, the transition to digital interaction dictates an increase in demand for new high-tech solutions in traditional areas of interaction with the customers. A breakthrough trend in this area was the emergence of digital currency and its own production. In the most expensive areas of service, such as international and foreign exchange payments, own-produced cryptocurrency based on blockchain technology allows foreign exchange payments to be made almost free. It is in these areas that an explosive growth in profitability and investment injections will be observed in the future. 


\section{Analysis of the Policy of the Mega-Regulator of the Financial Market}

Digitalization is a fairly capital-intensive process that requires a high budget, a trained team of specialists and channels to promote their proposals $[6,7]$. Therefore, the cheapening of the cost of credit resources in the context of online service seems to be a good way out of the situation of lack of funding for new intellectual projects. Today, business is trying to take into account market changes as much as possible based on the emerging trends. In fact, processing of colossal data and reports is required that a person is not physically capable of performing, therefore it is necessary to introduce Artificial Intelligence into the processes of analytical processing of large amounts of data. From this point of view, the active implementation of digital solutions by financial institutions and the replacement of mechanical labor with robotic ones seems logical. For the systematization and legal regulation of these processes in the financial market, it is necessary to form a regulatory platform based on the existing mega-regulator [8].

The Bank of Russia has been working on the development and implementation of the latest financial technologies in the work of the country's financial market for 2 years now. Let's note the most key positions and targets of the Russian banking system. (Fig. 3).

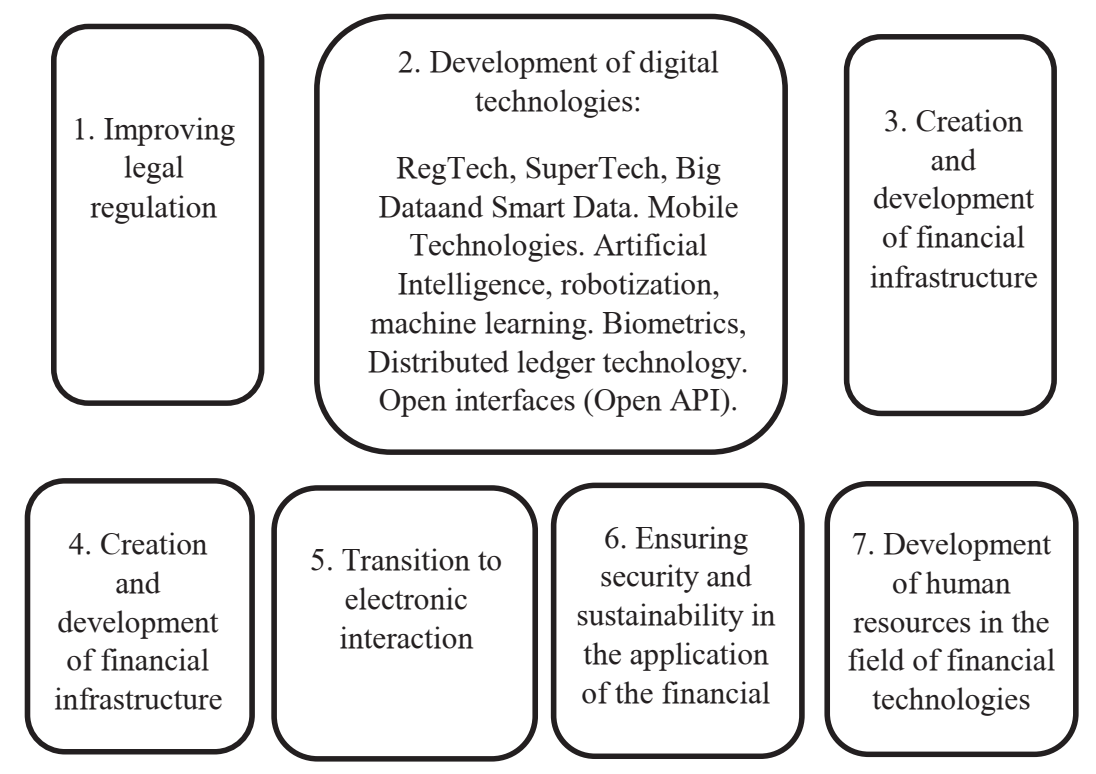

Fig. 3. Main directions of the Bank of Russia in the field of financial technologies, [5, 9]

The Bank of Russia has created its own regulatory platform for testing new digital solutions in the financial environment, which is a mechanism for coordinating and piloting the innovations. The goals of creating a regulatory mechanism, in addition to controlling the financial market, are to promote the new items on the financial market, to ensure legal regulation of the innovation process, to increase competition and accessibility of technologies, and to maintain the level of user safety [10]. 


\section{Conclusions}

To summarize this scientific research of the main trends in the digitalization of the financial sector of the economy, it should be noted that there has been a significant transformation of the previous architecture. In fact, modern financial institutions operate in a virtual space, developing and implementing the most advanced technologies for providing financial services and products in their own activities. Under the influence of environmental factors, these processes will only accelerate and become more complicated, therefore, in this case, it becomes necessary to coordinate and monitor the financial market. This function is performed by the Bank of Russia, which actually acts as a mega-regulator of the formation of a new financial architecture.

\section{References}

1. FINTECH 2019 annual financial technology market research in Russia, https://bloomchain.ru/

2. Main directions of financial technology development for the period of 2018-2020, https://cbr.ru/

3. On The strategy for the development of the information society in the Russian Federation for 2017-2030, decree of the President of the Russian Federation dated May 9, 2017 No. 203

4. On the approval of the information security Doctrine of the Russian Federation, decree of the President of the Russian Federation dated 05.12.2016 No. 646

5. On the national payment system, Federal law "" dated 27.06.2011 N 161-Ф3 (18.07.2017 No. 176-Ф3)

6. G. V. Fedotova, A. A. Gontar, E. I. Zubkova, Izvestiya of Yugo-Zapadnyu State University. Ser. Economy. Sociology. Management, 7 (2017)

7. V. Plotnikov, M. Golovko, G. V. Fedotova and M. Rukinov, Digital Economy: Complexity and Variety vs. Rationality, 87 (2020)

8. R. Lacko and F. Hurný, A. Rozkošová, Conceptual framework for evaluating the efficiency of public administration (2017)

9. R. Méndez Reátegui and D. G. Coca Chanalata, R Alosilla Díaz, The efficiency of public administration: A compartive analysis of the peruvian and ecuadorian cases from a neo institutional approach, 43 (2016)

10. A. Nasir, M. Shahzad, S. Anwar, S. Rashid, Digital governance: Improving solid waste management through ICT reform in Punjab (2017) 